\title{
La Poesía del "Papel Periódico de la Havana"
}

$E^{\mathrm{N}}$ los finales del siglo xvir, en que aparece el Papel Periódico de la Havana, y en los comienzos del siguiente, se fija la fecha inicial de la historia literaria en Cuba. Las tres centurias anteriores constituyen lo que podemos considerar como un período preliterario del que es, sin lugar a dudas, su último exponente, éste, nuestro primer periódico literario.

Poco o nada sabemos de las creaciones poéticas de nuestro aborigen, y sólo a través de las pobres noticias, perdidas las más veces entre el caudal de épicas acciones de las crónicas, llega a nosotros la actividad estética y social del areito, incapaz, por consiguiente, de influencia alguna posterior.

De los dos primeros siglos de la dominación española no restan más que datos, fidedignos unos, de muy dudosa autenticidad otros, sobre producciones literarias escritas en la isla además de nuestra más antigua creación poética: el poema en octavas, del canario Silvestre de Balboa, titulado Espejo de paciencia; siendo tan sólo en pleno setecientos cuando comienza para nuestra isla una ya ininterrumpida y no escasa, aunque estéticamente pobre, producción poética.

Pero, situados en la época que nos interesa, volvamos los ojos por unos momentos a Europa, y en ella a España, que es de donde continuarán casi exclusivamente, por algún tiempo, recibiendo sus influencias nuestras letras.

Se vive una de las centurias más trascendentales en la historia de la humanidad y está al sufrir su más violenta crisis, con la revolución francesa, una de esas épocas que, como dice Medardo Vi- 
tier (Las ideas en Cuba), juzgan agotada su savia vital y remueven, abaten, cancelan.

La gestación, empero, como ocurre siempre en estos casos, ha sido larga y laboriosa. $\mathrm{Y}$ ya, en los dos o tres siglos precedentes, se pone de manifiesto en muchos hombres que expresan lo que fermenta en todas las conciencias: la quiebra de las concepciones vitales hasta entonces vigentes -obra del Renacimiento- y la búsqueda angustiosa de otras nuevas.

Ambos aspectos -en realidad facetas de una misma piedraconstituyen así el antecedente, a primera vista lejano, de las tendencias literarias del siglo xvirr que, si no poco arbitrariamente deseáramos delimitar, hemos de distinguir en la imitación de los autores clásicos, con su consiguiente vuelta a la naturaleza - tal vez más que otra cosa, idolatría de la cultura, germen del racionalismo-, de donde surgirá el llamado neoclasicismo; y en el espíritu iconoclasta, censor y renovador de todos los órdenes del conocimiento, conocido después por criticismo, y latente desde que Descartes, antes que los hombres del 93, endiosa a la razón.

Introducida ya, realmente, en parte a través de Francia -a su vez bajo la influencia de los escritores italianos-, en parte por el contacto directo con las obras de estos últimos, como lo demuestran las imitaciones señaladas por Menéndez y Pelayo de Filicaja, Metastasio, Rolli, Frugoni y Parini, sin mencionar las influencias de la poesía latina, indiscutibles desde el siglo xv, lo cierto es que la tendencia clasicista - para la época neoclásica- activa su acción en España al advenimiento de Felipe V, el primero de los Borbones. La inquietud de la época se inicia, sin embargo, en toda su plenitud, en el campo de la erudición, de modo que, con la nueva familia reinante y su influencia transpirenaica, tendrán lugar la fundación de la Real Academia, de la Biblioteca Nacional (ambas en 1712), de la Academia de la Historia (1735) y la creación de las primeras sociedades llamadas de Amigos del País; la publicación del Diccionario de Autoridades (1726-1739), de la Ortografía (1741) y de la Gramática (1771) de la Real Academia; la aparición de los primeros papeles periódicos, entre ellos el célebre Diario de los Literatos (1737), al mismo tiempo que la Poética de Luzán, la Sátira contra los malos escritores de Jorge Pitillas, el Teatro Crítico Universal del padre Feijóo y las Fábulas de Iriarte y Samaniego, iniciándose la interminable contienda literaria en la que los ataques, tanto en el aspecto 
de las letras como en el de las costumbres, saturan por completo el ambiente de la península.

Es la época, por consiguiente, de la investigación y de la crítica, no de la poesía lírica, es decir - y reaparece Descartes, cuya sombra lo cubre todo-, la época de la razón. Por eso advertiremos en todo stu apogeo a la fábula y en general a las manifestaciones poéticas de tendencia utilitaria; por eso es poco frecuente que el poeta se nos dé en sus versos y usual que pretenda moralizar, enseñar.

Entonces el neoclasicismo triunfante en toda Europa, pues no escapan a él Italia, Inglaterra y Alemania, acaba por imponerse en España, predominando el espíritu horaciano de la sátira y de la oda filosófica a tono con los tiempos - esta última, germen quizás de una poesía posterior más subjetiva.

¿Cómo ha de permanecer la América española al margen de todo este hervor que caracteriza al siglo xvinI, cuando para las ideas no hay fronteras, ni océanos, ni trabas? Viajeros ilustres --franceses, españoles, alemanes- recorren y estudian el continente, despertando el espíritu investigador en el criollo. Se introduce en realidad - salvo excepciones como las de México y Perú, por ejemplo, que la tienen desde el siglo xvi- la imprenta; y es también cuando se trasplantan de la metrópoli las sociedades de Amigos del País y cuando se inicia la publicación de los primeros papeles periódicos.

En Cuba, la segunda mitad del siglo señalará el auge de lo que ha sido llamado por nuestros estudiosos el "colonialismo" -corriente progresista que, como ha manifestado el señor Enrique Gay-Calbó (Colonialismo), no fué sino un corto espacio de tiempo, si bien de trascendentales consecuencias, dentro de los cuatrocientos años de la dominación española-, en contraposición a lo "colonial", rapaz obtuso e inmisericorde; de modo que aquella corriente vivificadora será, encarnada en quien justamente ha sido llamado el mejor gobernante de Cuba colonial: don Luis de las Casas y Aragorri, la creadora del Papel Periódico de la Havana (1790-1805), puente de unión entre esa época por nosotros llamada preliteraria o, si se quiere, de antecedentes, y el siglo xix en que escribirán las más grandes figuras de nuestra historia literaria.

$$
\text { * } \quad * \quad *
$$

Mas ¿a qué estado habían llegado, en estos años iniciales de nuestro periodismo, las letras de la península? Como reacción a los 
despropósitos de todos los cultismos anteriores y, acaso más que por otras causas, por la tendencia racionalista que nos lleva como de la mano a la forma de expresión docente, es decir, sencilla, clara y trivial, habían caído en el más inconcebible prosaísmo. La poesía estaba llena de composiciones inspiradas en los temas más vulgares o antiestéticos - de lo que son inapreciable documento el poema "La pintura" de don Diego Rejón de Silva, y las "Excelencias del pincel y del buril", del grabador de cámara Juan Moreno de Tejada, infelices seguidores del no menos infeliz poema de Tomás de Iriarte "La música"-, flaquezas de las que no podía verse exenta la musa de los poetas más representativos de la época, y esto, con sus limitadas excepciones, cuando tal poesía, que en realidad había dejado de serlo, no aparecía como un torrente didáctico muy abundante de intención moralizadora, pero muy escaso también de caudal estético alguno. Postración contra la que se alza, empero, en las últimas décadas del setecientos, la llamada escuela neosalmantina cuya influencia, a través de los temas puramente líricos, vamos a advertir en el Papel Periódico a partir del año 1791.

Nuestra producción literaria no podía diferenciarse de la peninsular más que en el acrecentamiento de los defectos y de la vulgaridad, naturales al cabo en una sociedad de tan incipiente ambiente cultural como era la de aquellos años en la isla. De ahí que las poesías del Papel Periódico de la Havana reflejen, por lo tanto, y en términos generales, el ambiente literario de la metrópoli reducido a las dimensiones consiguientes a nuestro país; a más de que, hemos de tenerlo presente, no residía precisamente en el aspecto literario el valor de la clase de publicación en que aparecen, siendo por el contrario, el de entonces, como expresa acertadamente L. A. Sánchez, un periodismo de acuerdo con su época: investigador y científico, cuyo más puro espíritu podemos advertir en el prólogo de la segunda Gazeta de México - -uno de los primeros papeles periódicos del continente - cuando se expresa el propósito de brindar a los lectores "las tres razones de lo bueno: honesto, útil y deleitable".

El Papel Periódico nos fija, pues, precisa y diáfanamente, las tendencias literarias entonces en pugna, advirtiéndose en sus páginas -lo que confirman los libros anunciados por el periódico como recibidos de la península y puestos a la venta- el predominio de lo prosaico y racionalista de la escuela de Iriarte, al mismo tiempo que 
la influencia cada día creciente de las formas líricas de la reacción neosalmantina.

Conocidos tales antecedentes, y sin olvidar las caracteristicas propias del periodismo y las letras de la época, es interesante observar cómo esta poesía que ve la luz en las páginas de nuestro primer periódico literario aparece de un modo tímido, indirecto, si se prefiere, y no con plena independencia, es decir, que surge como argumento extremo en los artículos de costumbres por cuyo motivo han de salir varios números - seis, incluyendo el primero de 24 de octubre, hasta el correspondiente al domingo 28 de noviembre del propio año de 1790; el periódico sale este año sólo los domingos $\mathrm{y}$, a partir del siguiente, los jueves y domingos- para que aparezca la primera composición poética, ajena, y, como ya hemos dicho, solicitada por la tesis del articulista, la fábula de don Tomás de Iriarte "La rana y la gallina". Tendencia que mantendrá a esta poesía del Papel Periódico como apéndice o apoyo de la prosa hasta obtener su completa independencia, a mediados del 91 , con la aparición de las soledades, anacreónticas y letrillas; lo que por otra parte no implicará la ausencia de composiciones con su servidumbre inicial.

Otra característica peculiar, no ya a las producciones de los primeros tiempos del periódico, sino a las de toda su existencia, es la de no aparecer, más que en muy contadas excepciones, el nombre del autor, en el mejor de los casos encubierto bajo iniciales, seudónimos o anagramas, lo que podemos extender también, aunque evadiéndonos por un momento de los límites de este trabajo, a la prosa.

Si tenemos en cuenta que, como dice la fábula del propio periódico "Un librero y un erudito a la violeta", es entonces "la era en que brillan Iriarte, Samaniego e Ibáñez Rentería", y por consiguiente cuando la poesía es un arte esencialmente doctrinal, de ataque a las costumbres y en muchas ocasiones demasiado personal, no deja de ser perfectamente comprensible semejante interés del autor en ocultarse - hábito nada extraño tampoco entre los propios escritores de la península-; pero es muy probable se debiera en gran parte a una simple costumbre de la época, ya que, especialmente algunos de los anagramas utilizados, nos parecen hoy mucho más que transparentes y por lo tanto poco a propósito para quien tuviera en realidad intención de velar su personalidad, como sucede con los de 
Armenau Queizal, Ezequiel Armuna y Luis Fanerexe, los dos primeros pertenecientes indudablemente a Manuel de Zequeira, uno de nuestros primeros poetas, cronológicamente, y el tercero a Félix Veranes, celebrado orador sagrado y redactor del periódico.

Por estos años el poeta español Arriaza decía: "reina en la corte una plaga de fábulas como la pudiera haber de tercianas" y, ciertamente, en quienes recaían esas influencias no podía sino predominar el espíritu de enseñanza moral de tales composiciones.

Una breve ojeada al Papel Periódico es suficiente para advertir el número considerable de poesías de tendencias didácticas, dependientes o independientes de los trabajos en prosa, con el predominio consiguiente de las composiciones satíricas, donde no faltan tampoco fábulas, poco afortunadas por cierto, entre las que podemos distinguir algunas de relativo valor para las letras cubanas por cuanto significan intentos de adaptación al tema vernáculo, como la de "El tabaco verde y el gusano" y la de "El guacamayo, el carpintero y el cao". Séanos permitido, pues, transcribir, a pesar de su regular extensión y ausencia absoluta de méritos literarios, y sólo como un ejemplo del lamentable estado a que conducían las letras desđichados imitadores de Iriarte, la primera de estas fábulas:

\section{EL TABACO VERDE Y EL GUSANO}

Muy de mañana el Tabaco ostentaba lo vistoso de sus hojas y el Gusano que atento miraba todo, lleno de embidia le dice: por más que presumas loco tremolar pomposas hojas y ser de este campo adorno; yo mañosamente astuto, haré escala de tu tronco, y donde ellas llegaré hasta comer poco a poco las más frondosas, $y$ aquellas que te dan mayor adorno, con eso causará risa lo estropeado que te pongo

a lo cual atentamente el Tabaco dixo: Como te atreves vil Gusanillo con quien es útil a todos? Yo sustento muchos pobres, a distintas partes corro, $y$ en las faltriqueras ando como la plata y el oro. Por mi se aumenta el comercio y felicito ambos polos, siendo siempre útil aun cuando me veo reducido a polvo. Aun no hubo concluido, cuando el gusano furioso dió señas de acometer chispas soltando sus ojos. Le asaltó $\mathrm{y}$ a poco rato de estar en esto, matólo el Gañan que deshijaba la fertil vega. iQue propio le es este ejemplo a los que de embidia llenos y enojos 
quieren ser viles polillas de lo que han escrito otros; pues a modo de Gusanos a los libros más famosos. tal vez las mejores hojas quieren comer sino el todo: censurando y maldiciendo lo que no entienden, y como no hay quien les vaya a la mano sirven a la luz de estorvo!

Tras la lectura de tan pésima prosa rimada se comprenderá lo innecesario de todo nuevo comentario; aunque posteriormente insistiremos sobre el interés exclusivamente local que pueda tener la fábula transcrita.

Como algo esencial a todo este género de poesías, reñido invariablemente, en mayor o menor grado, con la belleza, vemos desfilar ante nuestra vista los defectos y costumbres de la época, no escaseando aquellos que, inherentes a la condición humana, pertenecen a todas y a ninguna, con algunos de sus personajes fundamentales como el afeminado, la mujer que no es más que una paleta de pintor, el petimetre, etc., donde no es difícil advertir cómo el ideal perseguido por los cultivadores del género estaba en constituirse en censores de la sociedad para -olvidando todo propósito estético- fustigar sus vicios; síntoma, acaso, de que tales composiciones, ingenuamente satíricas por regla general, representaban un estado de revaloración - todavía netamente español ; vivido en la propia metrópoli- que, iniciándose por entonces, iba a ser el antecedente de los movimientos emancipadores.

En cuanto a la producción propiamente lírica, no tiene escasa representación en las páginas del periódico como a primera vista pudiera creerse, y ya antes de cumplir el año la publicación aparece representada principalmente por el tema de la dorada mediocridad caro a Horacio, no por influencia directa, indiscutiblemente, sino a través de la poesía peninsular que, desde fray Luis de León, tan suyo lo había hecho.

La primera de estas composiciones publicadas (correspondiente al número de mayo 26, año 1791), que comienza :

iO amada soledad que venturoso

Haces que viva yo sin la codicia

Del oro por quien dexa la estulticia

La dulce paz del alma y su reposo! 
señala el vuelo lírico de la generalidad de estas odas no exentas, en la mayoría de los casos, de versos afortunados; aunque todas palidecen, sin embargo, ante los siguientes magníficos sáfico-adónicos, también de evidente corte horaciano, que no hemos resistido a la tentación de incluir en el presente trabajo:

Dame, Polimnia, tu dorada lira,

Préstame tonos armoniosos, cuando

Canto de Luisa metros inocentes;

Díctame, Musa.

Linda vecina del Parnaso monte...

¿Quedo! ¡Silencio! La divina Luisa

Ya se presenta; sus torneadas manos

Tocan el clave.

¿Cómo suspenso queda el auditorio

A la muy grande música destreza

Con que la joven imitarte sabe,

Grata natura!

Ya me parece que a la margen fresca

De un arroyuelo que entre guijas corre

Oigo el susurro que su clara linfa

Forma cayendo;

$Y$ que en la copa de robusto cedro

Mil pajarillos rebolando alegres

Limpios amores con ligeros trinos

Cantan acordes;

Ya me parece por la madrugada,

Enmudecidas las pasiones nuestras,

Oigo admirado el concierto süave

De las esferas:

$Y$ que en su giro la estrellada cumbre

Va pregonando con sonotas voces:

Vengan mis hombres; de mi Dios adoren

Las maravillas.

El que de penas fatigado corra,

Ansias sufriendo que vericer procura,

Tenga consuelo peregrina Luisa,

Oiga tu clave.

E1 que quisiete las virtudes mismas

Ver dibujadas con celeste razgo,

Luisa modesța, con respeto fácil

Mire tu cara.

Juntas las gracias la corona tejan

Que se te debe, y a tu frente ciñan

Rosas $y$ mirtos y laureles verdes. 
Versos que no los hubieran desdeñado poetas consagrados de la península y que son, como se observa fácilmente, una bellísima imitación de las liras a Francisco Salinas del autor de "Noche serena".

Las soledades, así como las letrillas, anacreónticas, etc., en las que se canta, bien a la vida humilde o retirada, bien a los ojos o a las inconstancias de la amada, elevan, como es de advertir, el valor literario de la publicación y constituyen una influencia poderosa para la época, patente tanto en la gran notoriedad adquirida por algunas de las composiciones publicadas (como la traducción de Metastasio titulada la "Despedida de Nise", según Bachiller y Morales aprendida de memoria por todos los amantes de las letras), como en las palabras de cierto anónimo articulista, según el cual, por obra de la comedia, el periódico y las mujeres, era "difícil ser joven y vivir en la Havana sin tener deseos de hacer versos".

La lírica religiosa apenas se halla representada en el Papel Periódico por escasas y pobres composiciones no escritas en la isla. En general parecen provenir de la península y, la de más valor -el soneto a Jesús crucificado transcrito a continuación-, del Mercurio Peruano. Dice, pues, este soneto:

A vos cortiendo voy brazos Sagrados

En la cruz sacro-santa descubiertos:

Que para recibirme estáis abiertos,

$Y$ por no castigarme estáis clavados,

A vos ojos divinos eclipsados,

De tanta sangre y lágrimas cabiertos:

Que para perdonarme estáis despiertos,

$Y$ por no confundirme estáis cerrados.

A yos clavados pies para no huirme:

A vos cabeza baxa por llamarme:

A vos sangre vertida para ungirme:

A vos costado abierto quiero unirme;

$A$ vos clavos preciosos quiero atarme,

Para vos ser unido, atado y firme.

Sus catorce versos representan la aparición del tema religioso en las páginas del periódico y fueron publicados, con el seudónimo de "El Nuevo Augustino", en el número de diciembre 8 del 91, advirtiéndose en ellos las inevitables influencias místicas españolas 
-que no hemos logrado precisar-, y ciertas semejanzas con algunas de las redondillas de los "Siete Soliloquios" amorosos de un alma a Dios, de fray Lope Félix de Vega Carpio.

En lo que se refiere al aspecto formal, en las poesías del Papel Periódico indudablemente predominan, dado el espíritu de la época, las combinaciones métricas de tipo tradicional, destacándose la décima - composición típica de nuestra musa popular - con una indiscutible supremacía sobre toda otra, si bien es cierto no le va muy a la zaga - y ya dentro de las formas italianas - el soneto, que constituye así la otra clase de composición poética más cultivada en las páginas de nuestro periódico. Por regla general poseen estos sonetos el cuarteto normal italiano ABBA y los tercetos CDC-DCD o CDE-CDE, excepto unos pocos que tienen el tipo $\mathrm{CDC}-\mathrm{CDC}$, no muy corriente a nuestro entender en la lírica castellana, o el menos usual CDD-CDD. No faltan tampoco, en estos primeros vagidos de nuestra prensa literaria, algunos pobres alardes de rebuscamiento formal, como los representados por el soneto en verso alejandrino traducido del francés (de noviembre 29 del 95), en el que sólo riman las palabras "cuenta" y "tiempo"; y por el infeliz y no poco disparatado "Romance esdrújulo" de "El Marquez Nueya", imperfecto aunque transparente anagrama de Manuel de Zequeira, al que pertenecen los siguientes versos:

\footnotetext{
Ya que en verso endecasilabo

Sapientísimo Luisiánico

Entre los sabios sofísticos

Puedes pasar por oráculo;

$Y a$ que en rutilantes, fúlgidos

Destellos del verso enfático

Sabes cual lobo finisimo

Rugit conceptos Gerárdicos:

Permite que un sabio frívolo

Temeroso... [roto el pliego]

Te tribute en tono rústico

Estos Esdrúxulos lánguidos.
}

Cumpliendo con el propósito manifestado por sus primeros redactores, de publicar algunos "retazos" de literatura —que es lo que lo convierte en nuestra primera publicación literaria-, el Papel Pe- 
riódico de la Havana no sólo lo hace, como hemos visto, con producciones de ingenios insulares, sino que también lleva a sus "papeles" otras de autores tanto hispanoamericanos o peninsulares como extranjeros; aunque las de estos últimos -incluyendo las de los clásicos latinos, en su mayor parte citas.o fragmentos, salvo contadas excepciones como la traducción libre en pareados, de Ovidio, por el presbítero José Agustín Caballero, redactor del periódico e iniciador, desde su cátedra en el Seminario de San Carlos, de la reforma filosófica en Cuba- son poco apreciables, siendo en realidad lo más notable cierta traducción de Poe, en síntesis un nuevo aporte a la numerosa serie de odas a la soledad, razón por la que expresa el señor Chacón y Calvo, con sobrada razón, y en su interesante estudio sobre los "Orígenes de la poesía cubana", que, al menos directamente, no hay más influencias en las letras de la época que las españolas.

Del Perú fueron publicados en 1791 algunos trabajos, entre los que podemos incluir el ya citado soneto a Jesús crucificado, además de la popularísima "Despedida de Nise", traducida de Metastasio; figurando, entre los poetas españoles cuyas composiciones inserta nuestro periódico, Lope de Vega, Iriarte y Arriaza, principalmente. Es curioso, no obstante, el hecho de aparecer algunas poesías que, si bien publicadas bajo seudónimos - creados por los redactores indudablemente-, o como producciones anónimas, pertenecen en realidad a figuras de mayor o menor relieve en las letras de la metrópoli. Tal es lo que sucede con el soneto de Juan Bautista Arriaza titulado "Mis deseos" — soneto por algunos atribuído a Iriarte-, que comienza:

Si Dios omnipotente me mandara

De sus dones tomar el que quisiera...

publicado sin nombre alguno de autor en el número correspondiente a enero 25 del 95, con pequeñas variantes respecto al que se halla entre las obras del poeta (tomo 67 de la B. de A. E.) ; y con otros dos que llevan, como si fueran de una misma persona, el seudónimo de "El Incógnito". De éstos, uno, el que con el título de "E1 jugador" se publica en abril 25 de 1805 , no es sino el soneto del mismo nombre del propio Juan Bautista Arriaza; y el otro, "Descripción del Currutaco", de febrero 24 de 1805, es, realmente, el atribuído al emeritense Juan Pablo Forner y titulado "Definición de un petimetre" (tomo 63 de la B. de A. E.), con la particularidad de aparecer modi- 
ficados casi por completo - para adaptar la composición al ambiente de la isla - sus cuartetos, que pierden evidentemente con el cambio.

Escribe su soneto J. P. Forner bajo el título ya mencionado de "Definición de un petimetre" y dice así:

Yo visto, ya ve usted, perfectamente;

Mis medias son sutiles y estiradas;

Las hebillas, preciosas y embidiadas;

Los calzones estrechos sumamente:

Charretera a la corva cabalmente;

Mis muestras, de Cabrier, muy apreciadas,

Mis sortijas en miles valüadas;

Sombrero de tres altos prepotente:

Sé un poco de francés y de italiano,

Pienso bien, me produzco a maravilla.

Soy matcial y a las damas muy atento.

¿Tengo, señor, razón de estar contento?

¿Qué me falta? No más que una cosilla:

Temor de Dios y algún entendimiento.

Y aparece en el Papel Periódico con el título de "Descripción del currutaco", en la forma siguiente:

Yo visto, ya ve usted, a la francesa,

La Balsa sé bailar y Contradanza,

Paso mi vida alegre en broma y danza,

Amenudo visito a una belleza.

Tengo negros, ingenios y dehesa,

$Y$ en este mismo dia justitamente

Me ha regalado un exquisito lente

Una amiga a quien trato con franqueza.

Sé un poco de francés y de italiano,

Pienso bien, me produzco a maravilla,

Soy marcial y a las damas muy atento.

¿Tengo, señor, razón de estar ufano?

¿Qué me falta? No más que una cosilla:

Temor de Dios, y algún entendimiento.

Compárense las dos formas transcritas anteriormente y se advertirá también cómo en el soneto del Papel Periódico la palabra, "ufano" substituye, en el primer verso del terceto final, a "contento", para mantener la rima con el verso inicial del primero, que inexplicablemente aparece destruída en la composición del poeta español; siendo sólo en esa insignificante corrección formal en el aspecto como 
pudiera aventajar nuestra versión a la española, al menos tal cual la conocemos hoy.

Hemos de llegar, pues, a la conclusión de que, en el mejor de los casos, los redactores de nuestra publicación carecían, como demuestran los sonetos anteriores, de ideas definidas sobre la propiedad intelectual o de lo que se ha dado en llamar piratería literaria; pero, al mismo tiempo, la lectura del soneto de Forner, modificado en las páginas del Papel Periódico de la Havana con el objeto de darle algún color local, especialmente en el aspecto de la economía propia de la colonia - "Tengo negros, ingenios y dehesa..."-, nos revela algo de indudable importancia para la historia de nuestras letras: el esfuerzo en busca de lo vernáculo irrumpiendo a través de los géneros didácticos y líricos del neoclasicismo imperante. Es ese espíritu que persigue el encuentro de la expresión propia -en estos períodos iniciales puramente externa- el creador de la fábula de "E1 tabaco verde y el gusano", donde no es ya sólo el tema lo netamente insular, sino hasta algunos de los vocablos empleados, como "deshijar" y "vega", verdaderos cubanismos en las acepciones de quitar los vástagos perjudiciales a las plantas y de siembra de tabaco, respectivamente.

Ambas composiciones - el soneto y la fábula - son por consiguiente, en las poesías del Papel Periódico, exponentes típicos de esa búsqueda de la expresión propia -aunque todavía vacilante como indican la adaptación o creación indistintamente de los temas poéticos, en gestación desde el poema de Silvestre de Balboa y a punto entonces de arribar a su culminación colonial con los poetas realmente cubanos del siglo xIX---, de la que sería absurdo excluir la innumerable cantidad de producciones satíricas que atestaban por entonces no sólo el nuestro, sino todos los papeles periódicos de Hispanoamérica.

A este espíritu peculiar que prestan por lo tanto al periódico algunas de sus composiciones, espiritu que pudiéramos llamar "nacional" en el sentido que a tal vocablo ha de darse de acuerdo con su época, hemos de añadir, empero, otro de no menor significación aportado por las poesías esencialmente líricas, y es el triunfo del subjetivismo sobre el intelectualismo, que se advierte ya, a pesar del evidente predominio didascálico, en las páginas del Papel Periódico. Es cierto que era el subjetivismo ficticio de las Cloris y de las Filis; 
pero siempre algo evidentemente muy superior al canto de loa o de circunstancias, al epigrama o a la poesía impersonal, en fin, que había sido hasta entonces la norma predominante.

El tema personal, es decir, el hombre interior, adquiere ahora, definitivamente, categoría en nuestras letras, mientras la pierde lo objetivo, lo externo, lo anecdótico e intrascendente que constituyó la característica de la poesía anterior; razón por la que apenas puede citarse alguna composición poética escrita en la isla antes de la aparición del Papel Periódico, en la que su autor haya puesto, con más o menos fortuna, su espiritu torturado o feliz, caso que podemos llamar excepcional de las décimas "A mis ojos", del poeta ciego Juan José Castro Palomino.

Por eso nuestra publicación, con sus letrillas, con sus anacreónticas, con sus odas, señala el advenimiento de una nueva época literaria en la que el nacimiento de un príncipe heredero o la muerte del monarca, el simulacro de ataque a una fortaleza o la sátira de costumbres, quedarán relegados al lugar que les corresponde en las letras. Porque, lo hemos dicho ya, nuestra producción literaria en los lejanos años finales del siglo xviII, representada especialmente por las poesías del Papel Periódico, era, en realidad, una reproducción de la cultivada en la metrópoli, a la que debía volverse exclusivamente en busca de orientación y contra la cual se alzará del marasmo anterior, en las primeras décadas del siglo XIX, su primer gran poeta netamente insular: José María Heredia.

Otto Olivera Ibarra, Louisiana State University, Baton Rouge, La. 